Journal of Mathematics and Informatics

Vol. 7, 2017, 45-52

ISSN: 2349-0632 (P), 2349-0640 (online)

Published 17 April 2017

www.researchmathsci.org

DOI: http://dx.doi.org/10.22457/jmi.v7a6

Journal of

Mathematics and

Informatics

\title{
Impact of Woman's Working Status on Spousal Abuse in Bangladesh: A Meta Analytical Review on Urban and Urban Slum Area
}

\author{
Md. Akhtarul Islam ${ }^{1}$, Tanvir Ahmed Mozumder ${ }^{2}$, Priyanka Ahmed ${ }^{3}$ \\ N.A.M Faisal Ahmed ${ }^{4}$ and Sk. Ariful Islam ${ }^{5}$ \\ Statistics Discipline, Khulna University, Khulna-9208, Bangladesh \\ ${ }^{1}$ E-mail: akhtarulstat@gmail.com; ${ }^{2}$ E-mail: tanvir.rizve@yahoo.com \\ ${ }^{3}$ E-mail: priyankaahmed136@gmail.com; ${ }^{4}$ E-mail: fahmed889@gmail.com \\ ${ }^{5}$ E-mail: arifulislam.ku.sk@gmail.com
}

Received 16 March 2017; accepted 10 April 2017

\begin{abstract}
To conduct a meta-analysis of trials evaluating the effect of woman's working status on domestic violence in Bangladesh with in urban and urban Slum area. A collection of different studies was considered based on Bangladesh urban and urban slum. Some studies were selected from well-known publication for meta-analysis purpose based on the working status along with study area. Primary data was also collected and analyzed to our purpose. Seven studies (Urban=4 and Urban Slum=3) with a significant results of woman working status. In urban area (i) Domestic violence on non-working woman is 2.07188 times of the working woman (confidence interval 1.0503, 4.08) (ii) Domestic violence on non-working woman is 1.12 times of the working woman (confidence interval 0.89, 1.4) (iii) Domestic violence on non-working woman is 1.6131 times of the working woman (confidence interval 0.674, 1.88) (iv) Domestic violence on non-working woman is 1.8 times of the working woman (confidence interval $0.99,3.4$ ). In urban slum (i) Domestic violence on non-working woman is 0.88 times of the working woman (confidence interval 0.532, 1.484) (ii) Domestic violence on non-working woman is 1.1.423 times of the working woman (confidence interval 0.629, 1.937) (iii) Domestic violence on non-working woman is 1.164 times of the working woman (confidence interval 1.031, 1.313). In summary the non-working woman are 1.622 times physically abused then the working woman (confidence interval 1.45744, 1.78626) where in slum area non-working woman are 1.147 times physically abused then the working woman (Confidence interval 1.0244, 1.257). In total the non-working woman have $30 \%$ more abuse rate in non-working woman then working woman (Confidence interval 1.183, 1.369). On the basis of meta-analysis we can conclude that in urban area non-working
\end{abstract}


Md. Akhtarul Islam, T.A.Mozumder, P.Ahmed, N.A.M.F.Ahmed and Sk. A.Islam woman are $62 \%$ more violated then the working woman and in slum area non-working woman are $14 \%$ more violated. On an overall summary non-working woman are $30 \%$ more physically abused then working woman.

Keywords: Meta-analysis, domestic violence, spousal abuse, urban area, slum area

AMS Mathematics Subject Classification (2010): 97K80, 91E45

\section{Introduction}

In our country $48.1865 \%$ of people are male and $51.813 \%$ of people are female. Though our country has a larger population of female, women are being violated in every step of their life whether economical or psychological or even physical. The patriarchal system of Bangladesh deprives women of their natural human rights. Sad but true most women come to believe that this mental, physical or any abuse is what they deserve. Even though the violence against women is nothing new in our country, its severity has received some attention due to some feminist scholars and activists in the past few years. Most common types of violence are domestic violence. In our country women are often seen as economic burden in their own home. Needless to say, it exacerbates when they go off to their husband's house. A woman spends most of her lifetime with her husband or his family. It is easy to manipulate and torture a girl growing up without any respect in her own home that a strange man or the person known as husband and his family takes full advantage to abuse that woman, knowing well that she is unable to control any wrong that is being done on her. And thus, it is not a surprising news that, according to WHO (2011) $87 \%$ of married women are victim of domestic violence.

\section{Materials and Methods}

\subsection{Literature search and study selection}

Publications of any size that analyzed relation between physical abuse and woman's working status based on Bangladesh journals were considered for inclusion along with the analyzed result based on the collected data in both urban and urban slum area.

\subsection{Data collection}

Data was collected from both urban and urban slum area to give a better view of recent situations in both area. For urban area the data was collected from Khulna city and for urban slum the data was collected from Mirpur slum, Dhaka. As all the well populated slums are in Dhaka we were obligated to select a slum in Dhaka. On the other hand Khulna city is a good representation of all the cities of Bangladesh. We didn't select Dhaka for our urban area as it has much more advance livelihood then other cities of Bangladesh.We have collected urban area data from Sonadanga residential area in Khulna district. From 712 households in Sonadanga residential area with the population of 2985 people, we selected 250 sample by Simple Random Sampling from the sampling 
Impact of Woman's Working Status on Spousal Abuse in Bangladesh:

A Meta Analytical Review on Urban and Urban Slum Area

frame of our population $\mathrm{N}=712$.From the 8 well known slum in Bangladesh, we have collected data from Mirpur Slum area. There are 658 household in Mirpur Slum with the population of 2232 people. We selected 252 sample by Simple Random Sampling from the sampling frame of our population, $\mathrm{N}=729$.

\subsection{Statistical analysis}

Sub group meta-analysis were used to conduct our analysis. The two groups are urban area and urban slum area. Meta-analysis were performed using odds ratios (ORs) for binary. The weight of each publication were assigned by the inverse of the variance of the OR of each study.Random effects models using the inverse variance weighted method approach were used to combine the data. To compute the confidence interval the mean effect along with the variance are used. Estimates were obtained using computer programs written in R and STATA. The forest plot was obtained using "magrittr" and "forestplot" package. In the case of tests of hypotheses, the article reports the value of the test statistics and associated P-values for different study variables. Effect measures have been considered to be statistically significant if the P-value is less than or equal to $5 \%$. Ninety five percent CI are presented for each effect measure.

For computing the effect size the computation were carried out on a log scale. The $\log$ odds ratio, and the standard error of the log odds ratio are computed and used to perform all steps in the meta-analysis. After that the results back into the original metric. The computational formula for Odds Ratio is

$$
\text { OddsRatio }=\frac{\frac{A}{B}}{\frac{C}{D}}=\frac{A D}{B C}
$$

The log odds ratio is then

$$
\text { LogOddsRatio }=\ln (\text { OddsRatio })
$$

With an approximate variance

$$
V_{\text {LogoddsRatio }}=\frac{1}{A}+\frac{1}{B}+\frac{1}{C}+\frac{1}{D}
$$

And approximate standard error

$$
S E_{\text {LogoddsRatio }}=\sqrt{V_{\text {LogoddsRatio }}}
$$

The log odds ratio and its variance are used in the analysis to yield a summary effect, Confidence limits into log units. Then each of the values are converted back to odds ratio

$$
\text { OddsRatio }=\exp (\text { LogOddsRatio })
$$


Md. Akhtarul Islam, T.A.Mozumder, P.Ahmed, N.A.M.F.Ahmed and Sk. A.Islam

$$
\begin{aligned}
& L L_{\text {OddsRatio }}=\exp \left(L L_{\text {LogoddsRatio }}\right) \\
& U L_{\text {OddsRatio }}=\exp \left(U L_{\text {LogoddsRatio }}\right)
\end{aligned}
$$

Here the LL and the UL represents the lower and the upper limits, respectively

After obtaining odds ratio for each of the study we assigned weight to each study.

$$
W_{i}=\frac{1}{V_{Y_{i}}}
$$

where $\mathrm{Y}_{\mathrm{i}}$ is the effect size and $V_{Y_{i}}$ is the within-study variance for study i-th study. The Weighted mean (M) is then computed as

$$
M=\frac{\sum_{i=1}^{k} W_{i} Y_{i}}{\sum_{i=1}^{k} W_{i}}
$$

The Variance of the summary effect size is then obtained as the reciprocal of the sum of the weights,

$$
V_{M}=\frac{1}{\sum_{i=1}^{k} W_{i}}
$$

The standard error is then obtained by the square root of the variance,

$$
S E_{M}=\sqrt{V_{M}}
$$

The $95 \%$ lower and upper limits for the summary effect are estimated as

$$
\begin{aligned}
& L L_{M}=M-1.96 \times S E_{M} \\
& U L_{M}=M+1.96 \times S E_{M}
\end{aligned}
$$

Finally, a z-value to test the null hypothesis that the common true effect is zero can be computed using

$$
z=\frac{M}{S E_{M}}
$$

For a one tail test the $\mathrm{P}$-value is given by

$$
p=1-\emptyset( \pm|Z|)
$$

\section{Results}

All of the studies agrees that working status has a significant effect on physical abuse by husband. In the urban area this effect is much greater than in urban slum.

\subsection{Discussion}

To get an updated point of view on our targeted population we have collected from both urban and urban slum area and analyzed data and for our meta-analysis we have used following studies

For urban area, 
Impact of Woman's Working Status on Spousal Abuse in Bangladesh:

A Meta Analytical Review on Urban and Urban Slum Area

Study-1: Our Study on urban area.

Study-2: Islam TM, Tareque Md. I, Sugawa M Kawahara K. "Correlates of Intimate Partner Violence against Women in Bangladesh".

Study-3: Sambisal W, Angeles G, Lance PM., Naved RT, Thornton J. "Prevalence and Correlates of Physical Spousal Violence Against Women in Slum and Non-Slum Areas of Urban Bangladesh".

Study-4: Abramsky T, Watts CH, Moreno CG, Devries K, LigiaKiss, MaryEllsberg, Jansen H AFM, Heise L. "What factors are associated with recent intimate partner violence?'. Source: WHO multi-country study on women's health and domestic violence.

For slum area, following studies are used.

Study-1: Our study on slum area.

Study-2: Salam Md. A, Alim Md. A, Noguchi T. "Spousal Abuse Against Women and Its Consequences on Reproductive Health: A Study in the Urban Slums in Bangladesh"

Study-3: Sambisal W, Angeles G, Lance PM., Naved RT, Thornton J. "Prevalence and Correlates of Physical Spousal Violence Against Women in Slum and Non-Slum Areas of Urban Bangladesh".

In our study we have seen that, in the slum area the odds of getting physically abused by the husband is 4.8484 times of the woman of the urban Area. In urban area we can see that physical abuse by husband is $68.61 \%$ higher for arrange marriage compared to the love marriage. In the slum area, the odds of this abuse is 2.6851 times of the love marriage compared to arrange marriage. In both areas respondent who agreed on the marriage, the odds of physical abuse by husband is around $66 \%$ less than those who didn't agreed. In urban area with increased education the odds of getting abused is decreased. The odds of getting physically abused for the respondent who has higher study than H.S.C is $90 \%$ less compared to the respondents who didn't go to school. The odds of the abuse in not employed respondents is double of the respondent who are unemployed but in the slum, there is not much effect of woman empowerment.

We have done Meta-Analysis to provide the collection of result of individual research result and to compare those results with the result obtained by our study. The studies were divided into two groups, urban and urban slum. All the studies were based on population of Bangladesh. In the study both the dependent and independent variables are dichotomous. The dependent variable is whether woman is physically abused by her 
Md. Akhtarul Islam, T.A.Mozumder, P.Ahmed, N.A.M.F.Ahmed and Sk. A.Islam husband or not and the independent variable was if the woman have any kind of income source. Each study is weighted by the inverse of their individual variance. Then weighted mean effect size for both urban and urban slum area is computed. Also the summarized effect is computed. In both areas at 5\% significant level of confidence interval the summary effect of woman's working status in both areas have significant effect on spousal abuse.

Table 1: Odds Ratio of physical violence by husband with other factors

\begin{tabular}{|c|c|c|c|c|}
\hline \multirow[b]{2}{*}{ Associated Factor } & \multicolumn{2}{|c|}{ Urban Area } & \multicolumn{2}{|l|}{ Slum Area } \\
\hline & $\begin{array}{l}\text { Odds } \\
\text { Ratio }\end{array}$ & $\begin{array}{l}\text { Confidence } \\
\text { Interval }\end{array}$ & Odds Ratio & $\begin{array}{l}\text { Confidence } \\
\text { Interval }\end{array}$ \\
\hline \multicolumn{5}{|l|}{ Area of residence } \\
\hline Urban Area & 1 & & 4.8484 & $3.314,7.094$ \\
\hline \multicolumn{5}{|l|}{ Marriage type } \\
\hline Love Marriage & 1 & & 1 & \\
\hline Arrange Marriage & 1.68617 & $0.878,3.237$ & 2.6851 & $1.298,5.553$ \\
\hline \multicolumn{5}{|c|}{ Willingness in the marriage } \\
\hline $\begin{array}{l}\text { Not Agreed on getting } \\
\text { married }\end{array}$ & 1 & & 1 & \\
\hline $\begin{array}{l}\text { Agreed on getting } \\
\text { married }\end{array}$ & 0.3491 & $0.195,0.624$ & 0.3445 & $0.200,0.592$ \\
\hline \multicolumn{5}{|l|}{ Respondent's Education } \\
\hline Didn't go to school & 1 & & 1 & \\
\hline Completed class 5 & 0.711 & $0.104,4.864$ & 2.347 & $1.215,4.535$ \\
\hline Completed S.S.C & 0.415 & $0.065,2.639$ & 1.249 & $0.609,2.561$ \\
\hline Completed H.S.C & 0.105 & $0.014,0.767$ & 1.857 & $0.159,21.718$ \\
\hline Higher study & 0.103 & $0.16,0.678$ & & \\
\hline \multicolumn{5}{|c|}{ Respondent's employment status } \\
\hline Employed & 1 & & 1 & \\
\hline Not employed & 2.072 & $1.050,4.087$ & 0.888 & $0.532,1.484$ \\
\hline
\end{tabular}

The summary effect size for the Urban area is 1.62185 thus in urban area the woman who are not working are likely to be 1.62185 times physically violated by their husband than the working woman. On the other hand in the slum area the effect size is 1.14727. Thus the woman who are not working in slum area are likely to be 1.14727 times more physically abused by the husband than the working woman.

From all the studies the summarized effect size is 1.30389. Thus non-working woman are likely to be 1.30389 times physically abused by the husband than the working woman. 
Impact of Woman's Working Status on Spousal Abuse in Bangladesh:

A Meta Analytical Review on Urban and Urban Slum Area

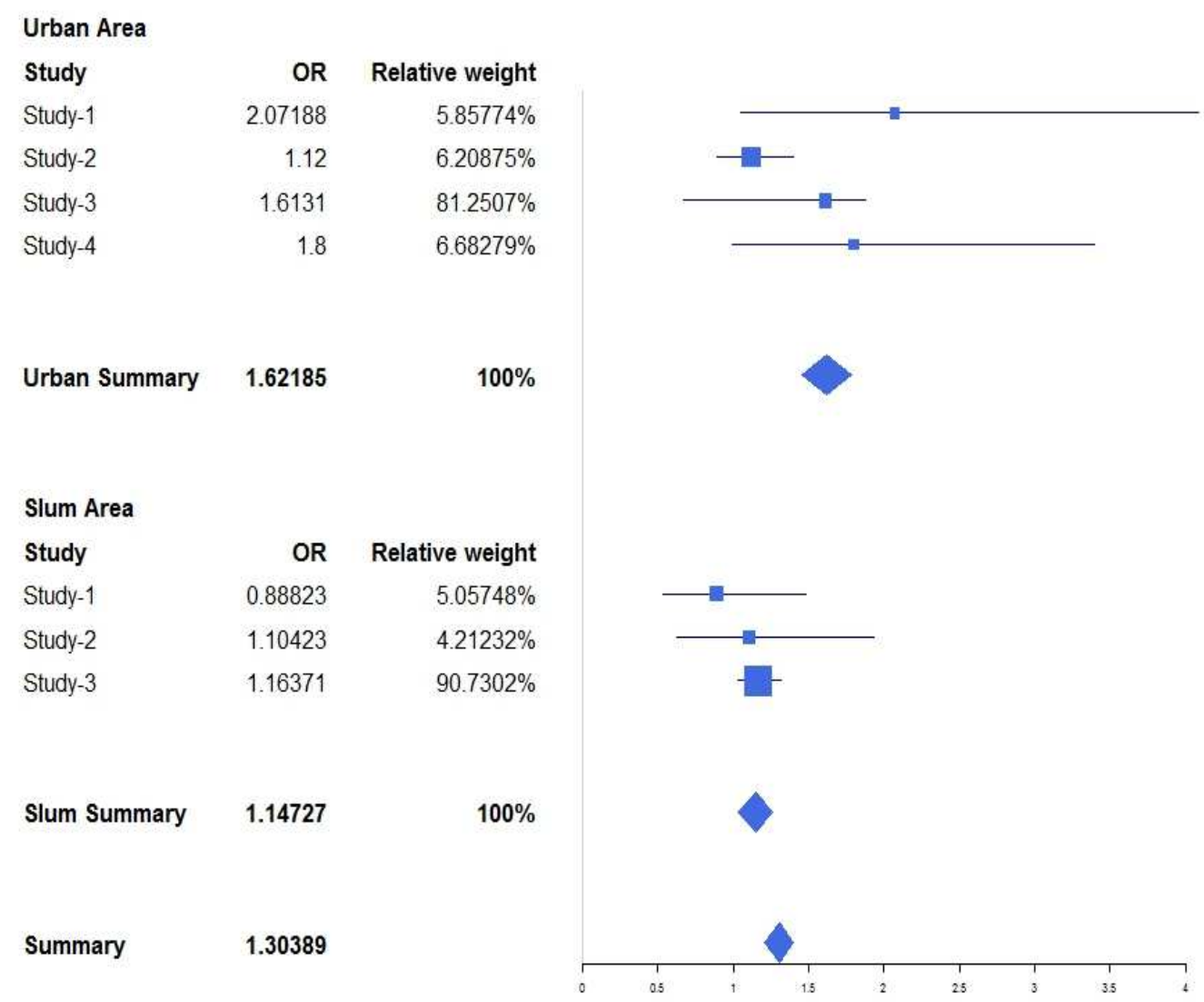

Figure 1: Forest Plot for the effect of women working status on physical abuse by husband

\section{Conclusion}

In our country woman are still being victim of spousal abuse. This rate is higher in urban slum then urban area. Woman's working status has a significant effect on this violence. We have seen that woman who earns money are less likely to be violated. The result from our study concludes that there is significant effect of woman working status on the spousal abuse. In urban area this effect is higher than in urban slum. Thus from our analysis we can conclude that to reduce physical abuse more opportunity for woman to work should be introduced to our society.

\section{REFERENCES}

1. T.M.Islam, M.I.Tareque, M.Sugawaand K.Kawahara, Correlates of intimate partner violence against women in Bangladesh, Journal of Family Violence, 30 (4) (2015) 433-444. 
Md. Akhtarul Islam, T.A.Mozumder, P.Ahmed, N.A.M.F.Ahmed and Sk. A.Islam

2. S.William, A.Gustavo, P.M.Lance, R.T.Naved and S.Curtis, Physical and sexual abuse of wives in urban bangladesh: husbands' reports, Studies in Family Planning, 41(3) (2010) 165-178.

3. A.Hetling and H.Zhang, Domestic violence, poverty, and social services: does location matter? Social Science Quarterly, 91(5) (2010) 1144-1163.

4. H.B.Johnston and R.T.Naved, Spousal violence in bangladesh: a call for a publichealth response, Journal of Health, Population and Nutrition, 26(3) (2008) 366-377.

5. S.R.Schuler, R.Lenzi, S.Nazneen and L.M.Bates, Perceived decline in intimate partner violence against women in bangladesh: qualitative evidence, Studies in Family Planning, 44(3) (2013) 243-257.

6. R.T.Naved and L.A.Persson, Factors associated with spousal physical violence against women in Bangladesh, Studies in Family Planning, 36(4) (2005) 289-300.

7. W.Sambisal, G.Angeles, P.M.Lance, R.T.Naved and J.Thornton, Prevalence and correlates of physical spousal violence against women in slum and non-slum areas of urban Bangladesh, Journal of Interpersonal Violence, 26 (13) (2011) 232-240.

8. L.M.Bates, S.R.Schuler, F.Islam and M.K.Islam, Socioeconomic factors and processes associated with domestic violence in rural Bangladesh, International Family Planning Perspectives, 30(4) (2004) 190-199.

9. S.J.Wang, J.Modvig and E.Montgomery, Household exposure to violence and human rights violations in western Bangladesh(I): prevalence, risk factors and consequences, BMC International Health and Human Rights, 9 (29) (2009) 18 p.

10. R.T.Naved, Sexual violence towards married women in Bangladesh, Arch Sex Behav. 42 (4) (2012) 595-602.

11. A.Salam, A.Alim and T.Noguchi, Spousal abuse against women and its consequences on reproductive health: a study in the urban slums in Bangladesh, Matern Child Health J., 10(1) (2006) 83-94.

12. R.Akhter and J.K.Wilson, Using an ecological framework to understand men's reasons for spousal abuse: an investigation of the Bangladesh demographic and health survey 2007, Source: Springer Science + Business Media New York 2015.

13. AbramskyT (1), Watts CH, Garcia-Moreno C, Devries K, Kiss L, Ellsberg M, Jansen HA, Heise L. (2011). "What factors are associated with recent intimate partner violence? findings from the WHO multi-country study on women' $s$ health and domestic violence", http://www.biomedcentral.com/1471-2458/11/109.

14. K.Parvin, N.Sultana and R.T.Naved, Disclosure and help seeking behavior of women exposed to physical spousal violence in Dhaka slums, BMC Public Health, (2016). 